\title{
FINITE-DISCRETE ELEMENT MODELLING OF MASONRY INFILL WALLS SUBJECTED TO OUT-OF-PLANE LOADS
}

\author{
Laura Liberatore $^{1}$, Marta Bruno ${ }^{1}$, Omar AlShawa ${ }^{1}$, Monica Pasca ${ }^{1}$ \\ and Luigi Sorrentino ${ }^{1}$ \\ ${ }^{1}$ Department of Structural and Geotechnical Engineering, Sapienza University of Rome \\ Via Gramsci 53, 00197 Rome, Italy \\ e-mail: \{laura.liberatore, marta.bruno, omar.alshawa, monica.pasca, luigi.sorrentino\}@uniroma1.it
}

Keywords: Masonry Infills, Out-Of-Plane Loads, Finite-Element Modelling, DiscreteElement Modelling, Non-Linear Analyses.

\begin{abstract}
In this paper, the out-of-plane response of infill walls is investigated by means of non-linear monotonic (push-over) analyses through a combined finite and discrete modelling approach. The model accounts for material deformability, crack formation, sliding, separation and formation of new contacts. Masonry units are modelled as finite elements, and different material models are assumed for the masonry. Contact between masonry units, and between masonry and frame elements is modelled by means of interfaces, which permit tangential motion with frictional sliding. Frame elements are modelled by means of a linearelastic material. The results of the numerical analyses are compared with those of experimental tests available in the literature. The advantages and disadvantages of the adopted modelling strategy are investigated.
\end{abstract}




\section{INTRODUCTION}

Masonry walls are widely used as infills in steel and reinforced-concrete (RC) frame structures. The failure of infills, which may develop both in- and/or out-of-plane, may cause casualties and heavy socio-economic consequences.

Recent earthquakes have shown that the out-of-plane failure of infills can occur even for moderate intensity of the ground motion $[1,2,3]$. For this reason, the interest in the out-ofplane behaviour of infill walls has been growing in the last years. A number of experimental tests have been performed by different investigators to assess strength and ductility of infill masonry walls loaded in the out-of-plane direction [4]. Moreover, several analytical models have been developed for the assessment of the out-of-plane response of masonry infills [5]. Most of them are based on rigid body mechanisms [6], either with or without the description of the arching behaviour.

More complex modelling is performed when numerical solution methods are adopted. These approaches involve either a smeared-crack or a discrete-crack modelling. The former is usually adopted to model the global behaviour of a structural system, while the latter is used to model the actual interaction between adjacent elements. The discrete-crack modelling can realistically predict the structural response when the crack pattern follows the locations of mortar joints [7].

The finite Element (FE) method has been applied more extensively to predict the in-plane behaviour for infills with [8] or without [9] openings. Some numerical studies are performed through the software DIANA [9, 10]. ANSYS software has been used by several researchers as well [11]; Mohyeddin et al. [12] have developed a three-dimensional FE model of infilled RC frames at a micro-level, showing that the model can be employed to interpret the response of the infilled frame under in- or out-of-plane loading over a wide range of drifts, allowing a parametric/sensitivity analysis [13].

Two classes of models can be identified [14]: discrete-crack modelling, including unit and joint model, with detailed micro modelling, where the material properties for the different components are generally taken from experiments [13, 14]; smeared-crack models, either weak or strong, for which a Total Strain Cracking Model is used to represent the material behaviour of the masonry [10] or macro-modelling of the masonry based on concrete smeared cracking and damaged plastic material (Concrete Damaged Plasticity model in Abaqus) [15].

A FE model is used to evaluate the out-of-plane capacity of an infill wall surrounded by a RC frame [10] with 3D curved-shell elements for both frame (8-node) and interface between infill and frame (6-node); mortar and unit-mortar interface are smeared out in the continuum. For the compressive and tensile behaviour of masonry the concrete material in the FE software DIANA is used. Two models are considered, depending on the boundary conditions of the infill wall, the first one representing two-way arching action, whereas the second represents one-way action.

FE modelling has been used also for the analysis of retrofitted infill masonry under out-ofplane loads [16], with simplified micro-modelling, where units are represented by continuum elements, mortar joints by interface elements, and reinforcing bars by truss elements; a more simplified FE model with equivalent vertical bars have been studied as well, in order to evaluate the sensitivity to modelling parameters. In this case the presence of the retrofitting reduces the sensitivity to variations of the material constants, which is usually rather high.

In this paper, the out-of-plane response of infill walls is investigated by means of nonlinear analyses through a combined finite and discrete modelling approach. The results of the numerical analyses are compared with those of experimental tests available in the literature. 


\section{MODELLING ASPECTS}

In order to reproduce the main characteristics of the response of different specimens of infill walls tested in the out-of-plane direction, several models are implemented using the LSDYNA software package [17], which is a finite-discrete element code capable of simulating three-dimensional problems. This code is used here, within an ANSYS environment, to numerically reproduce the results of experimental tests.

A combined finite and discrete modelling approach is used. Units are modelled as linear elastic 8-node solid elements with a single integration point. The major disadvantage of onepoint integration is the need to control the zero-energy modes that arise, called hourglassing modes, which might enlarge and destroy the solution. A Flanagan-Belytschko stiffness-type stabilisation is used here [18].

Mortar is not explicitly considered in the model; instead contact interfaces are used. Contact interfaces allow the transmission of both compressive and tensile forces, moreover a tangential motion with friction sliding is permitted. Frictional sliding occurs when the frictional stress limit is reached. In tension, the contact interface failure criteria is based on the normal tensile stress limit. In compression, to avoid the penetration between nodes and contact surface, the standard penalty method is used. The method consists in placing normal springs between all penetrating nodes and the contact surface. The interface stiffness depends on the stiffness of the materials that are in contact and on a scale factor, named penalty factor.

With the aim of comparison, FE models resorting to a smeared-crack approach are also implemented. In these cases, the contact surfaces are used only at the interface between the masonry panel and the surrounding structure.

Vertical loads are first applied to the system. Static or quasi-static processes can be simulated resorting to dynamic relaxation or to mass damping to eliminate dynamic oscillations. Preliminary analysis have shown that, for the cases at hand, the two methods give equivalent results. To avoid high frequency oscillations during the application of the gravity loads, these are applied slowly from zero to gravity acceleration. Afterward, horizontal displacements are applied in the out-of-plane direction.

\subsection{Material modelling}

Different types of material have been initially examined for modelling units: linear elastic (MAT_001), Winfrith smeared-crack concrete model (MAT_084/085), smooth-surface cap model (MAT_159), damage-plastic concrete model (MAT_273).

The linear elastic material (MAT_001) is particularly suitable when no damage is expected in the units, both in tension and compression, i.e. when the cracks pattern follows the joints. The use of this material requires the definition of a very limited number of parameters and allows to reduce the computational effort. However, given that the out of plane failure of infills may occur due to excessive compression in the units, a non linear material is more adequate to represent the actual behaviour.

The Winfrith material model (MAT_084-085) is a smeared-crack model developed in [19, 20]. The mechanical parameters that have to be defined are initial tangent modulus, Poisson's ratio, uniaxial compressive and tensile strengths. Moreover, a volumetric strain versus volumetric pressure curve is required. If the curve is omitted, a default pressure versus volumetric strain curve is automatically used. The Winfrith material includes also the option of considering reinforcement in a smeared fashion.

Material type 159 (MAT_159), which is available for solid elements, is a smooth-surface cap model, i.e. with a smooth intersection between the shear surface and the hardening cap [21]. This material has been created to reproduce accurately the response of concrete subject 
to impact loads. Many parameters, such as moduli, strengths, hardening, softening, and rate effects parameters, must be supplied, otherwise default values are provided. Default parameters are fit for unconfined compression strengths between about 20 and $58 \mathrm{MPa}$ and aggregate sizes between 8 and $32 \mathrm{~mm}$ and, therefore, are not suitable for the modelling of masonry. Given the difficulties in calibrating the parameters (more than thirty) with the experimental tests available for masonry materials, this material type was not used.

The damage-plastic concrete model (MAT_273) is based on the studies in [22][23], and is aimed to simulate the failure of concrete structures subjected to dynamic loads. The model is based on effective stress plasticity, with damage based on both plastic and elastic strain measures. The definition of the model requires a large number of parameters, but several of them are directly related to one another by explicit expressions. Other parameters can be determined from certain assumptions, or taken by their recommended default values [22], so that a limited number of material properties must be specified.

With the aim of highlighting the differences between these materials, a simple two-blocks model has been tested under compression (Figure 1). Input data are reported in Table 1. As already noted, values of the compression strength lower than $20 \mathrm{MPa}$ are incompatible with the material MAT_159. In this case the analysis runs out immediately. For the other material types, the vertical resultant force and the minimum principal stress are reported in Figure 2. The use of MAT_273 leads to a larger stiffness of the model and the analysis stops before the attainment of the material compressive strength, hence this material is not used in the following analyses. The Elastic (MAT_001) and Winfrith (MAT_084-085) materials give the same results in the elastic range, the latter presents a stiffness reduction when the displacements increase.

\begin{tabular}{lllllll}
\hline Material & $\begin{array}{l}\text { RO } \\
\left(\mathrm{kg} / \mathrm{m}^{3}\right)\end{array}$ & $\begin{array}{l}E \\
\mathrm{MPa}\end{array}$ & $v$ & $\begin{array}{l}A_{s} \\
\mathrm{~mm}\end{array}$ & $\begin{array}{l}f_{c} \\
\mathrm{MPa}\end{array}$ & $\begin{array}{l}f_{t} \\
\mathrm{MPa}\end{array}$ \\
\hline MAT_001 & 2200 & $2.8 \mathrm{E}+3$ & 0.2 & - & - & - \\
MAT_084-085 & 2200 & $2.8 \mathrm{E}+3$ & 0.2 & 1 & 2.84 & - \\
MAT_159 & 2200 & - & - & 1 & 2.84 & $5.69 \mathrm{E}-1$ \\
MAT_273* & 2200 & $2.8 \mathrm{E}+3$ & 0.2 & - & 2.84 & $5.69 \mathrm{E}-1$ \\
\hline RO = density; $E$ = Elastic modulus; $v$ = Poisson's ratio; and $A_{s}=$ Aggregate size; $f_{c}=$ compressive \\
strength; $f_{t}=$ tensile strength.
\end{tabular}

Table 1: Input values for different material types.

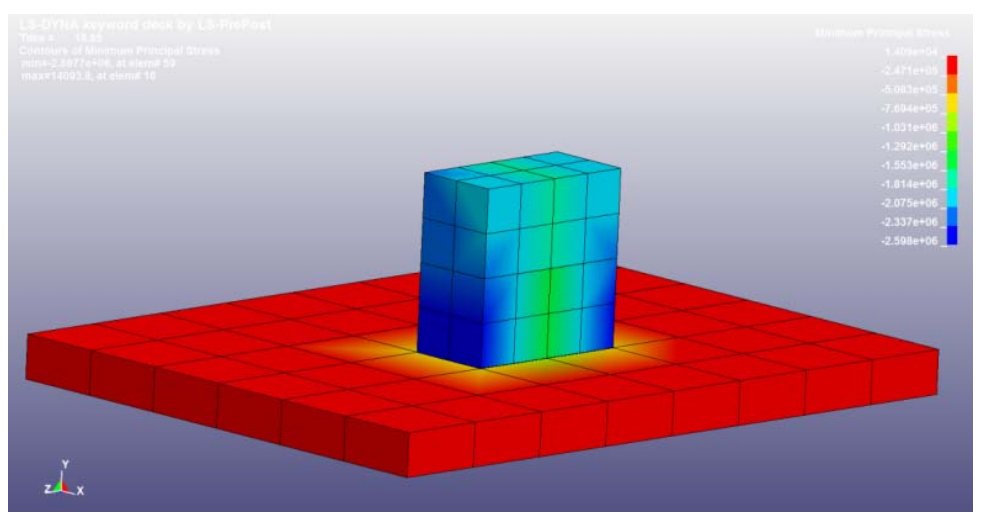

Figure 1: Two-blocks model: minimum principal stress. 

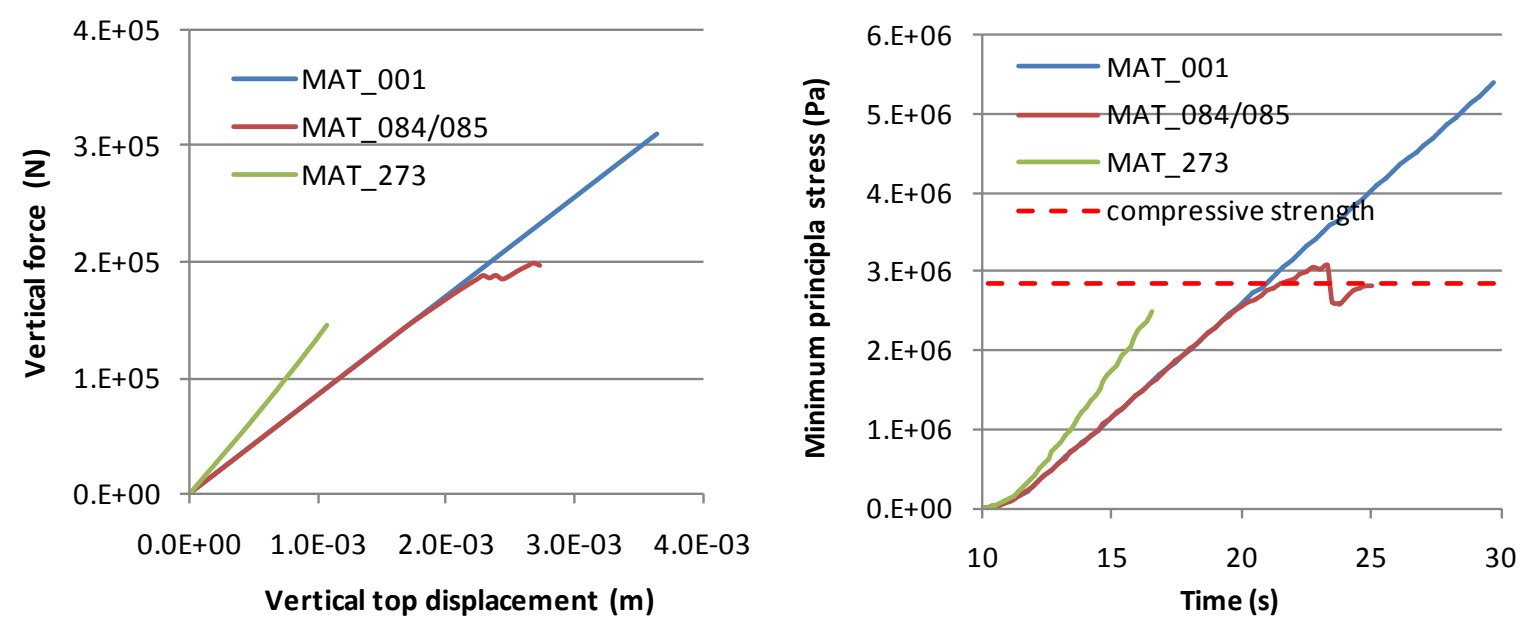

Figure 2: a) Force-displacement (a), and minimum principal stress-time plots (b).

\section{CASE STUDY}

Different models have been selected and analysed, in order to replicate the tests by Modena and da Porto [24]. This experimental investigation concerns nine hollow-block masonry panels $\left(976 \times 2520 \times 291 \mathrm{~mm}^{3}, b \times h \times t\right)$ loaded at mid-height by means of a horizontal rigid beam. At the top and the bottom the panels are mortared to rigid RC supports, whereas vertical edges are not restrained. Six specimens were constructed with horizontal-hole blocks, the other three specimens were constructed with vertical-hole blocks, thus achieving the masonry compressive strength necessary for arching behaviour. Consequently, out-of-plane strength of vertical-hole blockwork is almost thrice that of horizontal-hole one and is noticeably underestimated by available equations [5]. One of the vertical-hole specimens, FVC1, is considered in the following analyses.

In the numerical simulations have been used both the Elastic and the Winfrith materials, whose main mechanical characteristics are reported in Table 2. For the finite-discrete models, the mechanical characteristics of the units have been adopted, the tensile strength has been increased so that the tensile failure occurs in the contact interfaces. For the smeared-crack model, the masonry elastic modulus has been used and tensile strength is assumed equal to $20 \%$ of compressive strength. As far as the contact interfaces is concerned, the parameters that affect the global response are: the normal failure stress (in tension), the frictional stress limit, the coefficient of friction and the scale factor on default penalty stiffness (penalty factor). As observed in Section 2, the penalty factor is used to calculate the interface stiffness. For this parameter, a default value of 0.1 is recommended in the case of contact between similarly refined meshes of comparably stiff materials. However, according to [7] a value of 0.05 is expected to give reasonable results for masonry walls. To investigate the influence of this factor, three values of the penalty factor are used herein, i.e. $0.02,0.05$, and 0.10 . It is noted that this values are the product of two input parameters: SFS (or SFM), which is the scale factor included in the contact card, and SLSFAC, which is the scale factor for sliding interface penalties included in the control card.

The model geometry and the adopted mesh are shown in Figure 3. With the aim of capturing the stress field across the wall thickness, four finite elements are present in the transversal direction. Top and bottom supports are modelled as rigid bodies, so as the loading central beam. Prescribed horizontal displacements are assigned monotonically to the rigid beam up to $10 \mathrm{~mm}$. 


\begin{tabular}{|c|c|c|c|c|c|c|c|c|}
\hline & \multicolumn{5}{|c|}{ Units properties } & \multicolumn{3}{|c|}{ Contact properties } \\
\hline Model ID & Material & $E$ & $v$ & $f_{c}$ & $f_{t}$ & NFLS & SFLS & $\begin{array}{l}\text { Penalty } \\
\text { factor }\end{array}$ \\
\hline & & $\mathrm{MPa}$ & & $\mathrm{MPa}$ & $\mathrm{MPa}$ & $\mathrm{MPa}$ & $\mathrm{MPa}$ & \\
\hline M01 & Elastic & $20.83 E+3$ & 0.15 & - & - & 0.78 & 0.78 & 0.02 \\
\hline M02 & Elastic & $20.83 E+3$ & 0.15 & - & - & 0.78 & 0.78 & 0.05 \\
\hline M03 & Elastic & $20.83 E+3$ & 0.15 & - & - & 0.78 & 0.78 & 0.10 \\
\hline M04 & Winfrith & $20.83 E+3$ & 0.15 & 20.83 & 5.22 & 0.78 & 0.78 & 0.02 \\
\hline M05 & Winfrith & $20.83 E+3$ & 0.15 & 20.83 & 5.22 & 0.78 & 0.78 & 0.05 \\
\hline M06 & Winfrith & $20.83 E+3$ & 0.15 & 20.83 & 5.22 & 0.78 & 0.78 & 0.10 \\
\hline M07 $7^{(1)}$ & Winfrith & $5.22 E+3$ & 0.15 & 5.22 & 1.04 & - & - & - \\
\hline M08 $^{(1)}$ & Winfrith & $5.22 \mathrm{E}+3$ & 0.15 & 5.22 & 1.04 & - & - & - \\
\hline
\end{tabular}

$E$ = Elastic Modulus; $v$ = Poisson's ratio; $f_{c}=$ masonry compressive strength; $f_{t}=$ masonry tensile strength; NFLS = contact normal failure stress; SFLS = contact frictional stress limit.

${ }^{(1)}$ Smeared-crack modelling: elastic modulus is that of the masonry.

Table 2: Masonry and contact mechanical properties.

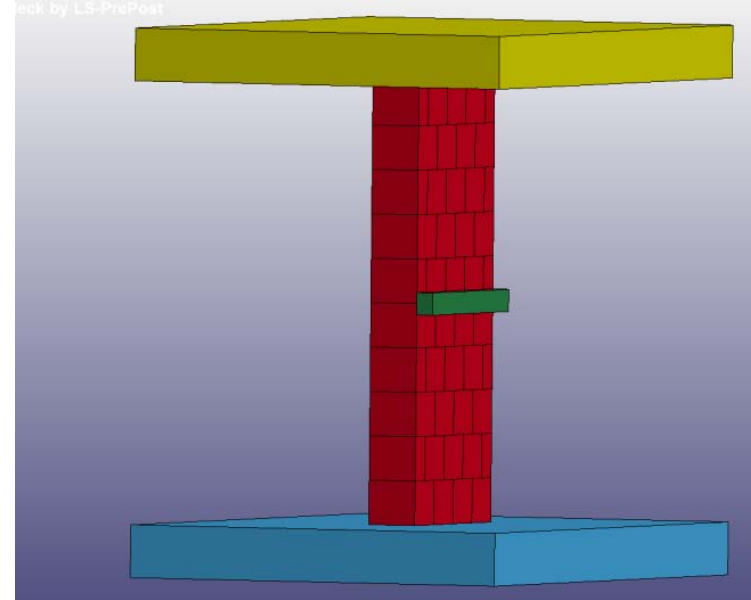

(a)

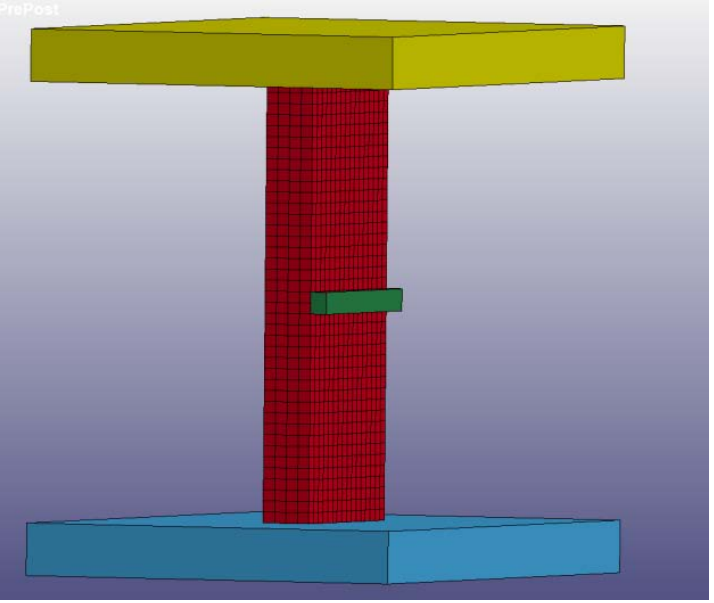

(b)

Figure 3: Model: a) geometry; b) mesh.

\subsection{Results}

Horizontal force resultant versus prescribed displacements are reported in Figure 4 for the numerical models and for the specimen. The models with the Elastic material (M01, M02 and M03) are less stiff compared to the experimental results. A moderate stiffness increase can be obtained increasing the compressive stiffness of the contact interface, i.e. with an increase of the penalty factor (Figure 4a). However, an increase of the penalty factor leads to deformations that are inconsistent with the experimental ones. The deformed shape and the principal compression stress for models M02 and M03 are reported in Figure 5. The model M02 present an horizontal crack at mid-height, in agreement with experimental results, while, in the model M03, a sliding occurs at the second course. As shown in Figure 6, the sliding starts abruptly at about $52 \mathrm{~s}$, when the displacement at mid-height of the wall is about $4.5 \mathrm{~mm}$. 
(a)

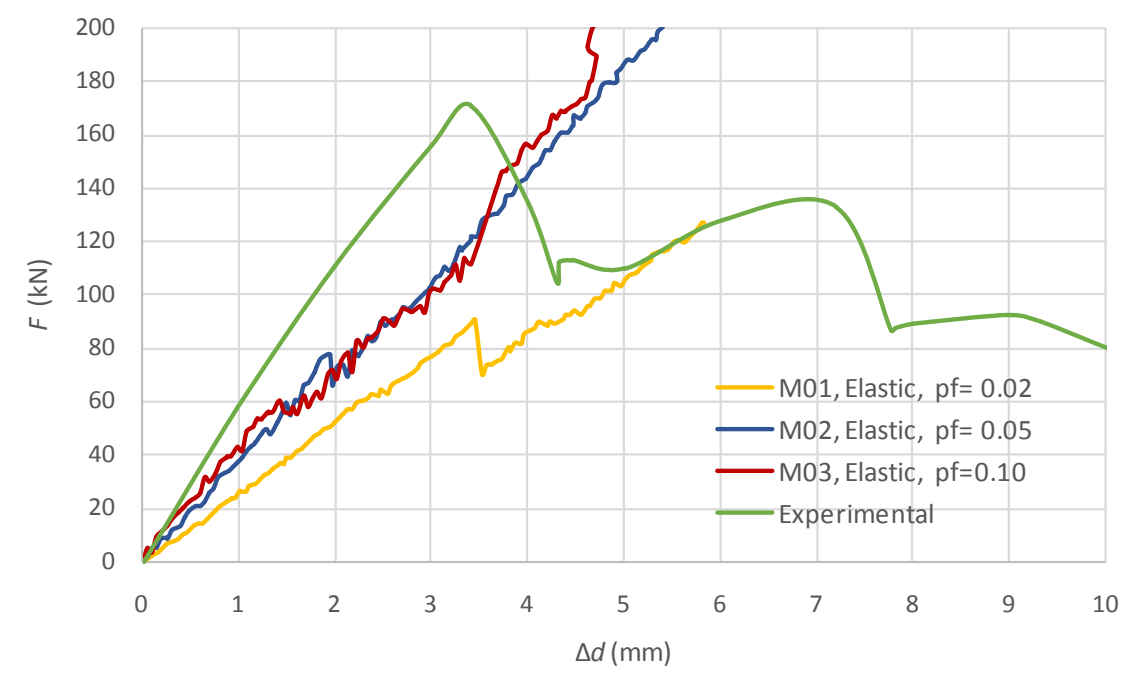

(b)
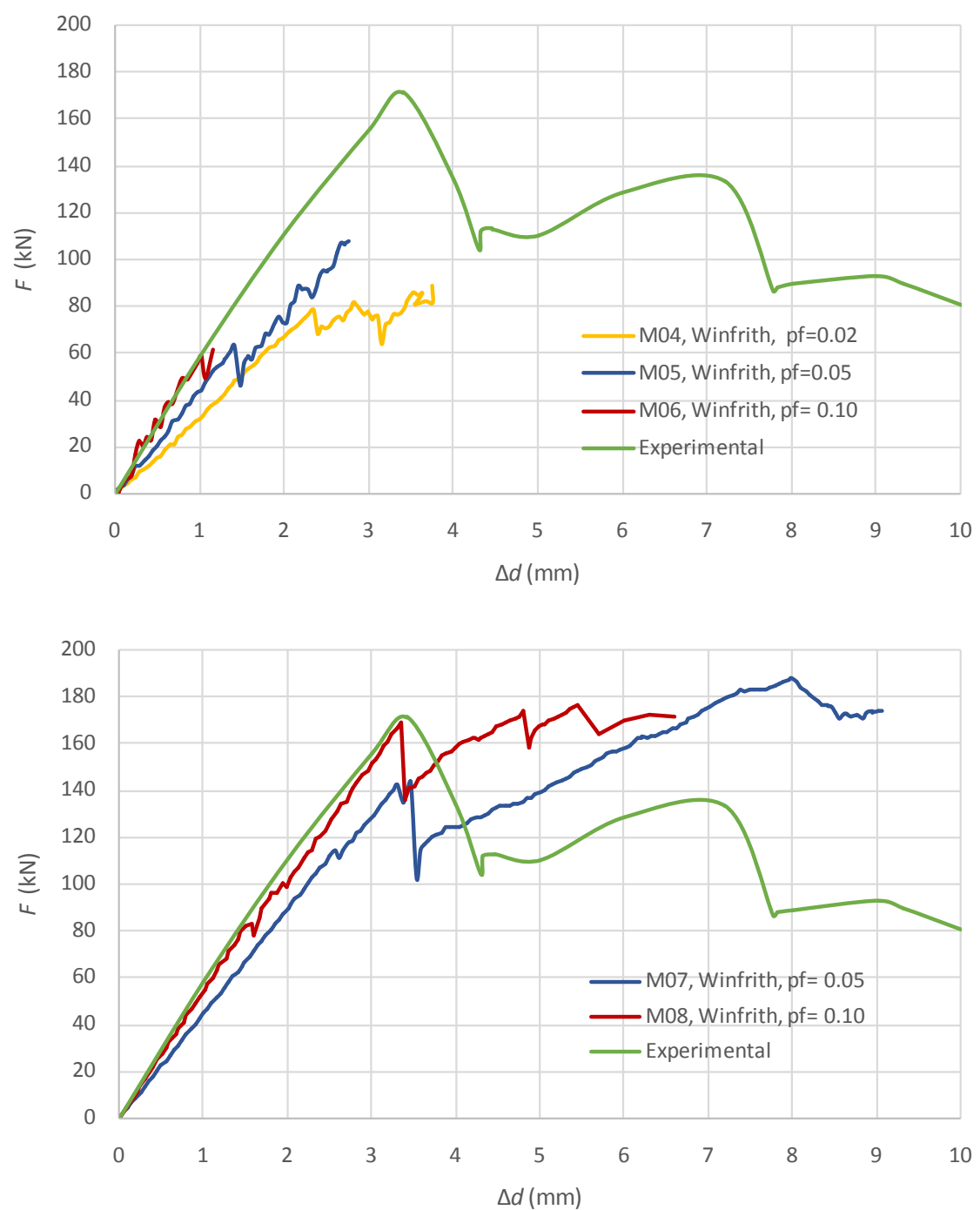

Figure 4: Horizontal force resultant versus prescribed mid-height displacements, experimental and numerical models: a) discrete-crack Elastic material; b) discrete-crack Winfrith material;

c) smeared-crack Winfrith material. 
In the case of the Winfrith material the increase of the penalty factor produces local stress increments and the earlier termination of the analysis. In fact, models M04, M05 and M06 do not terminate the analysis (Figure 4b) due to sudden increment of the principal compression stress, as shown in Figure 7. When the Winfrith material is used in a smeared-crack approach to model the blockwork, but interfaces are still present between masonry and RC frame, these local phenomena are avoided and the global response represents better the actual behaviour (Figure 4c). The stress distribution along the height of the walls is consistent with an arching behaviour (Figure 5c).

As observed, the finite-discrete models with higher penalty factors are not able to provide the maximum strength when the Winfrith material is adopted, whereas the smeared-crack models approximate better the experimental curve.

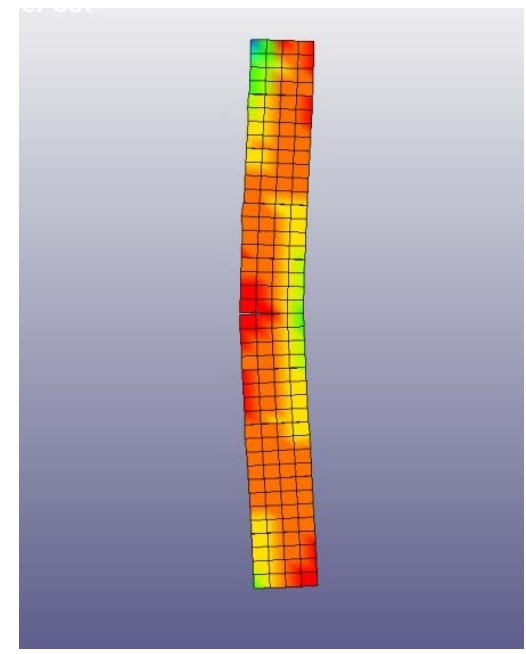

(a)

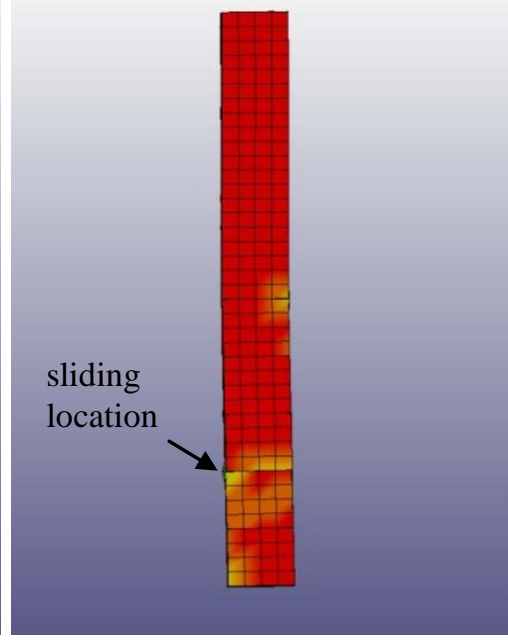

(b)

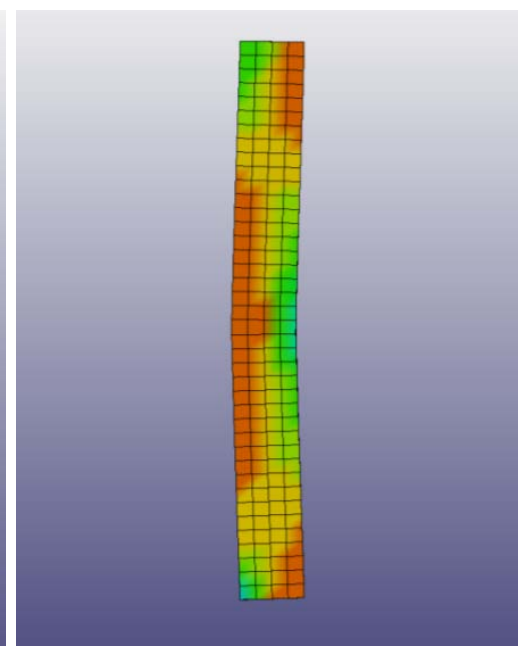

(c)

Figure 5: Deformed shape and principal compression stresses for models: a) M02; b) M03; c) M07. Displacement are not to scale.

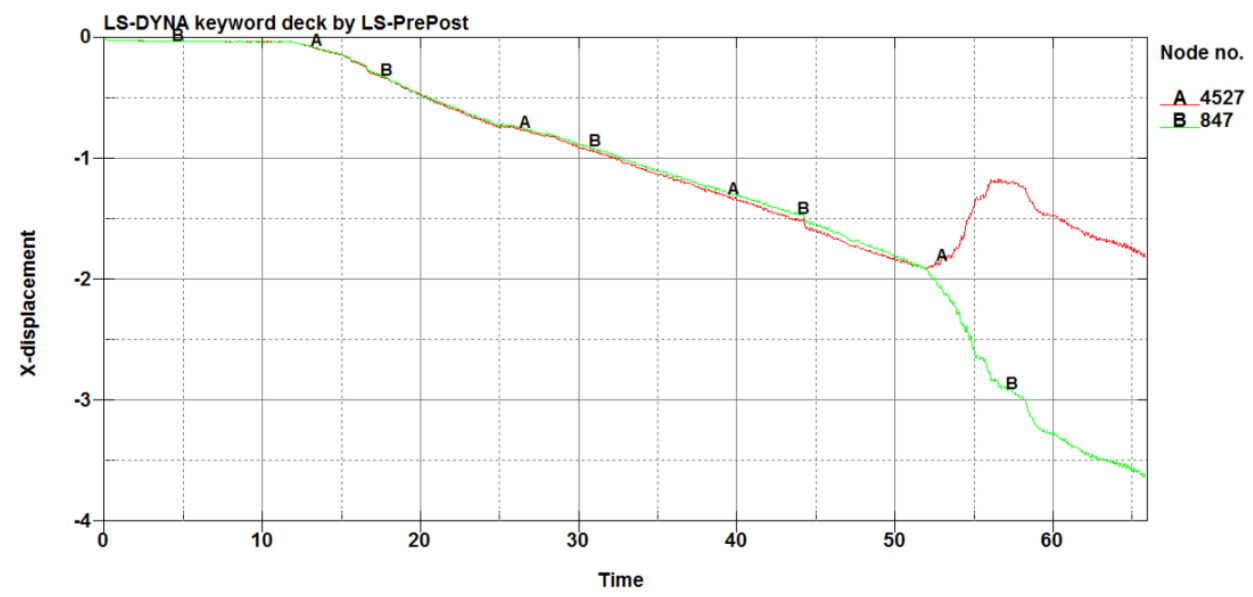

Figure 6: Model M03, horizontal displacement (mm) time history (s) at second course (see Figure 5b). Red line: displacement of the upper surface; green line: displacement of the bottom surface. 


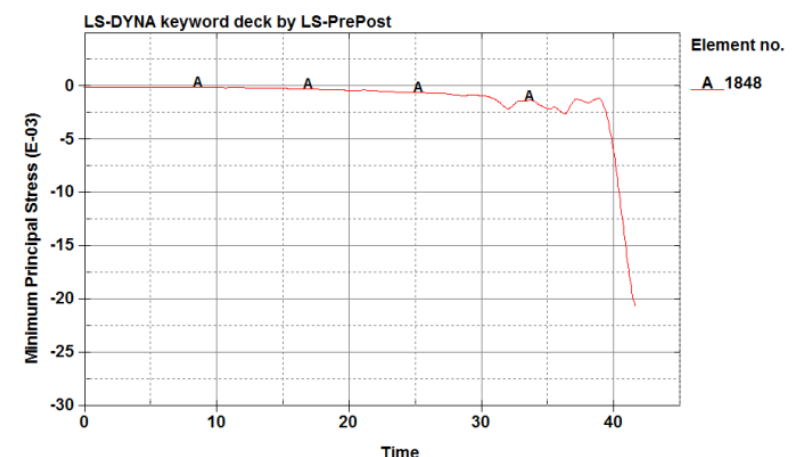

(a)

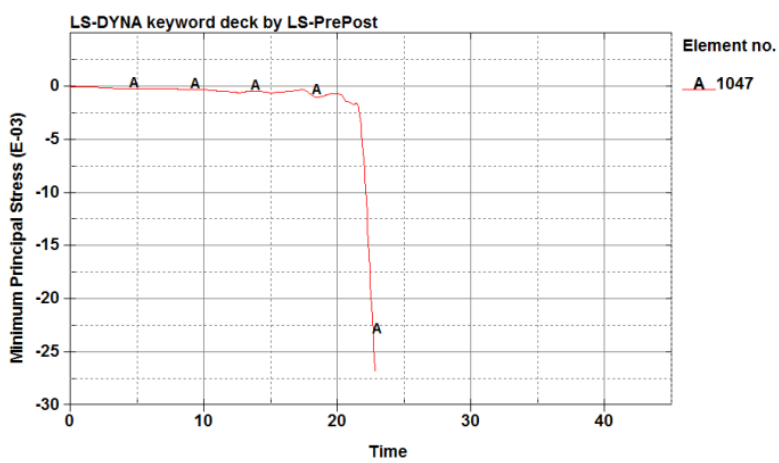

(b)

Figure 7: Minimum principal stress $\left(\mathrm{kN} / \mathrm{mm}^{2}\right)$ time history (s) in the most compressed elements for models: a) M04; b) M05.

\section{CONCLUSIONS}

In this paper the out-of-plane response of infill masonry panels is modelled through a discrete-finite element approach. Interfaces are present between masonry units, as well as between blockwork and reinforced-concrete frame. For the sake of comparison a smeared-crack approach has been also used to model masonry.

It is concluded that, when using a finite-discrete method, the stiffness of the contact interfaces is one of the most important parameters affecting the solution, because modifies the global stiffness of the model, if an elastic material is used for the blocks. When a non-linear material is used, in addition to the modification of the model stiffness, a local increment of stress occurs, leading to the earlier termination of the analysis. These shortcomings are avoided in a smeared-crack approach, reproducing better the experimental results, while still resorting to contact surfaces at the interface between masonry panel and surrounding structure.

\section{ACKNOWLEDGEMENT}

The financial support of the Ministry of the Instruction, University and Research of Italy (MIUR) is gratefully acknowledged. This work has been partially carried out under the programs "Dipartimento della Protezione Civile - Consorzio RELUIS", signed on 2015-12-31, Masonry Constructions, General and Territorial Topics. The opinions expressed in this publication are those of the authors and are not necessarily endorsed by the Dipartimento della Protezione Civile.

\section{REFERENCES}

[1] L.D. Decanini, A. De Sortis, L. Liberatore, F. Mollaioli, Estimation of near-source ground motion and seismic behaviour of RC framed structures damaged by the 1999 Athens earthquake. Journal of Earthquake Engineering, 9(5), 609-635, 2005.

[2] L.D. Decanini, L. Liberatore, F. Mollaioli, Damage potential of the 2009 L'Aquila, Italy, earthquake. Journal of Earthquake and Tsunami, 6(3), 1250032:1-32, 2012. 
[3] L. Hermanns, A. Fraile, E. Alarcón, R. Álvarez, Performance of buildings with masonry infill walls during the 2011 Lorca earthquake. Bulletin of Earthquake Engineering, 12, 1977-1997, 2014.

[4] L. Liberatore, M. Pasca, Out-of-plane response of infill masonry walls. $9^{\text {th }}$ International Masonry Conference (IMC), Guimarães, Portugal, July 7-9, 2014.

[5] L. Liberatore, M. Pasca, Assessment of the Out-of-plane Resistance of Masonry Infill Walls. 15th International Conference on Civil, Structural and Environmental Engineering Computing (CIVIL-COMP), Prague, Czech Republic, September 1-4, 2015.

[6] L. Sorrentino, R. Masiani, M.C. Griffith, The vertical spanning strip wall as a coupled rocking rigid body assembly. Structural Engineering and Mechanics, 29(4), 433-453, 2008.

[7] S. Burnett, M. Gilbert, T. Molyneaux, G. Beattie, B. Hobbs, The performance of unreinforced masonry walls subjected to low-velocity impacts: Finite element analysis. International Journal of Impact Engineering, 34, 1433-1450, 2007.

[8] X. Chen, Y. Liu, Numerical study of in-plane behaviour and strength of concrete masonry infills with openings. Engineering Structures, 82, 226-235, 2015.

[9] V.G. Haach, G. Vasconcelos, P.B. Lourenço, Parametrical study of masonry walls subjected to in-plane loading through numerical modeling. Engineering Structures, 33, 1377-1389, 2011.

[10] A.A. Tasnimi, E. Zomorodi, The Effect of Onplane Behavior on Inplane Interaction of URM Infilled RC Frame Under Lateral Loads. $14^{\text {th }}$ European Conference on Earthquake Engineering, Ohrid, Macedonia, August 30 - September 3, 2010.

[11] R Kanit, M.S. Döndüren, Investigation of using ansys software in the determination of stress behaviours of masonry walls under out of plane cycling load. International Journal of the Physical Sciences. 5(2), 97-108, 2010.

[12] A. Mohyeddin, H.M. Goldsworthy, E.F. Gad, Sensitivity analysis of nonlinear behaviour of infill-frames under in-plane and out-of-plane loading. Advances in Structural Engineering. 16(10), 2013.

[13] A. Mohyeddin, H.M. Goldsworthy, E.F. Gad, FE modelling of RC frames with masonry infill panels under in-plane and out-of-plane loading. Engineering Structures. 51, 73-87, 2013.

[14] J.R. Van Noort, Computational modelling of masonry structures, Master Thesis, Delft University of Technology, August 23, 2012.

[15] P. Agnihotri, V. Singhal, D.C. Rai, Effect of in-plane damage on out-of-plane strength of unreinforced masonry walls. Engineering Structures, 57, 1-11, 2013.

[16] A.C. Shrestha, T. Nagae, Y. Araki, Finite element modeling of cyclic out-of-plane response of masonry walls retrofitted by inserting inclined stainless steel bars. Journal of Disaster Research. 6(1), 36-43, 2011.

[17] LSTC 2013. LS-DYNA Keyword User's Manual. Livermore: Livermore Software Technology Corporation.

[18] J.O. Hallquist, LS-DYNA Theory Manual. Livermore: Livermore Software Technology Corporation, 2006. 
[19] B.J. Broadhouse, A.J. Neilson, Modelling Reinforced Concrete Structures in DYNA3D. Report: AEEW-M 2465, Safety and Engineering Science Division, United Kingdom Atomic Energy Authority. Winfrith Technology Center. Dorchester, UK October-1987.

[20] B.J. Broadhouse, The Winfrith Concrete Model in LS-DYNA3D. Report: SPDID(95)363, Structural Performance Department, Atomic Energy Authority Technology. Winfrith Technology Center. Dorchester, UK February-1995

[21] Y.D. Murray, A Abu-Odeh, R. Bligh, Evaluation of LS-DYNA Concrete Material Model 159. US Department of Transportation, Federal Highway Administration, Report FHWA-HRT-05-063, 2007.

[22] P. Grassl, M. Jirásek, Damage-plastic model for concrete failure. International Journal of Solids and Structures, 43, 7166-7196, 2006.

[23] P. Grassl, U. Nyström, R. Rempling, K. Gylltoft, A damage-plasticity model for the dynamic failure of concrete. Eurodyn 2011, 8th International Conference on Structural Dynamics, Leuven, Belgium, 2011.

[24] C. Modena, F. da Porto, Experimental investigation on the out-of-plane seismic behaviour of masonry infills. Research Report, Draft 1, Department of Constructions and Transportations, University of Padua, Italy, 2005. (In Italian). 